\title{
An audit of enteral tube feeding in the acute hospital setting; evaluation of current practice and identification of areas for further investigation and development
}

\author{
C. O’Neill, A. Lyons, N. Connolly, E. Fanning, R. Hannon, S. McMahon, H. Guiden, K. McElligott \\ and G. Corrigan \\ Beaumont Hospital, Dublin, Ireland
}

Enteral tube feeding (ETF) has been comprehensively reviewed in the past and its effectiveness and indication for use meet strong agreement $^{(1)}$. As per Duval ${ }^{(2)}$ an audit tool is useful to evaluate the effects of treatment and may influence the development of clinical pathways and service provision. Thus, an audit of ETF was undertaken in a Dublin teaching hospital to evaluate current practise and shape future service delivery.

A quantitative retrospective audit was completed over a 1 month period. All patients commenced on ETF during this period or already established on ETF were included $(n=80)$. Patients in the intensive care unit were excluded. Data was recorded in an Excel spreadsheet and presented as a percentage of $n=80$. The primary outputs included ETF indications, route, incidence of refeeding syndrome, glycaemic control and reasons for suboptimal delivery.

The mean age was 63.8 years (range $21-95$ years) and the mean weight was $83.1 \mathrm{~kg}$ (range $28.2-138 \mathrm{~kg}$ ) with $51 \%$ of patients having a body mass index (BMI) within the normal range (18.5-24.9). The average length of ETF was 57.5 days (range 2-757 days), it must be highlighted that this was skewed by one long term feed patient. The following table is a brief synopsis of the main outcomes and results.

\begin{tabular}{ll}
\hline Outcomes & Results \\
\hline Routes of delivery & Nasogastric 55.5\% $(n=43)$ \\
& Gastrostomy feeding $36 \%(n=26)$ \\
Indications for ETF & Swallowing disorders $31.2 \%(n=25)$ \\
& Post-operative nutrition $17.5 \%(n=14)$ \\
Interruption to feed delivery & $58.2 \%(n=46)$ \\
Causes of delivery interruption & Tube dislodgement $28 \%(n=13)$ \\
& Fasting for procedure $28 \%(n=13)$ \\
Raised blood glucose levels & Nausea and vomiting $20 \%(n=9)$ \\
Refeeding syndrome & $>10$ mmols $/ 14 \%(n=7$ known diabetic, $n=2$ received steroids $)$ \\
\hline
\end{tabular}

This audit identified nasogastric and gastrostomy feeding as the most common routes of ETF. Swallowing disorders and post-operative nutrition support were the main indications for ETF. Tube dislodgement and fasting for procedure were found to be the most common causes for suboptimal delivery of feed. Blood glucose control and identification and management of refeeding syndrome were highlighted as areas that would benefit from further investigation and development in this clinical setting. Hence, work is currently being undertaken to develop policy on these areas.

1. Stratton RJ, Green CJ \& Elia M (2003) CAB International.

2. Duval K, Marceau P, Perusse L \& Lacasse Y (2006) Obes Rev 7, 347-360. 